\title{
ALTERNATIF STABILITAS TIMBUNAN DENGAN BATASAN KORELASI PARAMETER TANAH SEPANJANG TOL SERANG-PANIMBANG MENGGUNAKAN SLOPE-W
}

\author{
oleh : \\ Azzah Balqis Sabbah \\ Teknik Sipil Universitas Negeri Semarang \\ Email : azzahbalqis@mail.unnes.ac.id \\ Retno Mayasari \\ Teknik Sipil Universitas Negeri Semarang \\ Email : retnomayasari@mail.unnes.ac.id \\ Isna Pratiwi \\ Teknik Sipil Universitas Negeri Semarang \\ Email : isnap@mail.unnes.ac.id
}

\begin{abstract}
Abstrak : Penelitian ini mengkaji mengenai variasi batas tinggi timbunan jalan yang dapat dibangun pada proyek Tol Serang - Panimbang umumnya berada pada tanah kohesif. untuk lokasi yang berada pada tanah khusus seperti tanah organik tidak dibahas dalam artikel ini. Hasil parameter tanah diambil melalui dua tahap yaitu site investigation dan pengujian laboratorium. Parameter yang digunakan sebagai dasar perhitungan yaitu NSPT, c, $\phi$, dan $Y$. Untuk menyederhanakan analisa dibuat korelasi parameterparameter tanah dasar dari kombinasi antara hasil data pengujian lapangan dan data laboratorium yaitu berat jenis tanah, kohesi dan sudut geser menghasilkan 5 layer tanah yaitu layer 1 (Nspt: 0 - 4, c:4 kPa, $\phi: 10^{\circ}, \Upsilon: 15 \mathrm{kN} / \mathrm{m}^{3}$ ), layer 2 (Nspt: 5 - 8, c:10 kPa, $\phi: 10 \circ, \Upsilon: 16 \mathrm{kN} / \mathrm{m}^{3}$ ), layer 3 (Nspt: 9 - 12, c:18 kPa, $\phi: 10$ o,,$: 16 \mathrm{kN} / \mathrm{m}^{3}$ ), layer 4 (Nspt: 13 - 15, c:26 kPa, $\phi: 10^{\circ}, \Upsilon: 17 \mathrm{kN} / \mathrm{m}^{3}$ ), layer 5 (Nspt: 16 - 20, c:30 kPa, $\phi: 10$ o , $\Upsilon: 17 \mathrm{kN} / \mathrm{m}^{3}$ ). Pemodelan tinggi timbunan sepanjang $50 \mathrm{~km}$ berkisar pada $0-15 \mathrm{~m}$ dari permukaan tanah dasar dengan slope 1:2 menggunakan Slope-W 2012. Tiap layer dimodelkan dengan variasi tinggi timbunan 0 - $15 \mathrm{~m}$. Apabila faktor keamanan slope sudah lebih dari 1.5 maka variasi tersebut yang menjadi batas minimum tinggi timbunan dan minimum nilai Nspt tanah dasar timbunan. Hasil penelitian menunjukkan bahwa slope dengan ketinggian maksimum $7 \mathrm{~m}$ harus berada di tanah dasar Nspt minimum 5 - 8, ketinggian 8 - 11 m harus berada di tanah dasar Nspt minimum 9 - 12, ketinggian 12 - 15 m harus berada di tanah dasar Nspt minimum 13 - 15.
\end{abstract}

Kata Kunci : faktor keamanan, korelasi parameter, Nspt, slope, tinggi timbunan.

Abstract : This research examines the variation of road embankment height along the Serang - Panimbang toll road project, generally on cohesive soil. The location has special soils such as organic soils, but it will be not discussed in this article. The soil parameters were taken through two stages, namely site investigation and laboratory testing. The parameters used as the basis for the calculation are NSPT, $c, \phi$, and Y. For simplifying the analysis, a correlation of subgrade parameters is made from a combination of the results of field test data and laboratory data, namely soil density, cohesion and shear angle resulting in 5 soil layers, namely layer 1 (Nspt: 0 - 4, c: $4 \mathrm{kPa}, \phi: 10 \mathrm{o}, \mathrm{Y}: 15 \mathrm{kN} / \mathrm{m}^{3}$ ), layer 2 (Nspt: 5 - 8, c: $10 \mathrm{kPa}, \phi: 10 \mathrm{o}, \mathrm{r}: 16 \mathrm{kN}$ $/ \mathrm{m}^{3}$ ), layer 3 (Nspt: 9 - 12, c: $18 \mathrm{kPa}, \phi: 10 o, r: 16 \mathrm{kN} / \mathrm{m}^{3}$ ), layer 4 (Nspt: 13 - 15, c: $26 \mathrm{kPa}, \phi: 10 \mathrm{o}, \mathrm{r}: 17 \mathrm{kN}$ $/ \mathrm{m}^{3}$ ), layer 5 (Nspt: $16-20, \mathrm{c}: 30 \mathrm{kPa}, \phi: 10 \mathrm{o}, \mathrm{r}: 17 \mathrm{kN} / \mathrm{m}^{3}$ ). Modeling of the embankment height ranges from 0-15 $\mathrm{m}$ from the subgrade surface with a 1: 2 slope using Slope-W 2012. Each layer is modeled with a variation of $0-15 \mathrm{~m}$ heights. If the slope safety factor is more than 1.5, then this variation becomes the 
minimum limit of embankment height and the minimum value of the subgrade Nspt. The results show that the slope with a maximum height of $7 \mathrm{~m}$ must be on the subgrade Nspt minimum 5-8, 8 - $11 \mathrm{~m}$ height must be on the subgrade Nspt minimum 9-12,12 - 15 m height must be on the subgrade Nspt minimum 13 - 15.

Keyword : Safety factor of embankment, parameter correlation, Nspt, slope, the height of embankment.

\section{Pendahuluan}

Kestabilan timbunan merupakan salah satu keutamaan dalam desain perencanaan geoteknik. Kestabilan lereng timbunan adalah kondisi yang mantap/stabil terhadap bentuk dan dimensi lereng (Duncan, et al, 2004). Salah satu faktor kestabilan timbunan bergantung pada daya dukung tanah dasar, kuat geser tanah, rencana tinggi, dan kemiringan dari timbunan (Hadiyatmo, 2006). Daya dukung tanah dasar berguna untuk menopang beban timbunan. Sedangkan kemiringan dan tinggi timbunan menjadi faktor besarnya beban yang akan ditahan oleh tanah dasar. Apabila kestabilan timbunan tidak dijaga maka resiko keruntuhan seperti longsor yang dapat terjadi di sepanjang badan jalan serta slope timbunan. Dari 3 faktor penting penentu kestabilan timbunan tersebut, kemiringan dan tinggi timbunan yang dapat dikontrol dan dibatasi saat proses desain jalan.

Pengontrolan batas tinggi timbunan dan kemiringan pada ruas tol Serang Panimbang dilakukan saat proses desain aliyemen vertikal dan horizontal trase jalan. Proses desain trase jalan (termasuk aliyemen vertikal dan horizontal jalan) membutuhkan control guide untuk mengetahui batasan tinggi dan kemiringan timbunan. Apabila trase didesain berdasarkan control guide batasan tinggi dan kemiringan timbunan, maka desain akan mengurangi resiko penambahan perkuatan untuk kestabilan timbunan yang berdampak pada biaya. Analisis desain geoteknik juga akan lebih mudah dalam mengelompokkan area mana saja yang harus diberi penambahan perkuatan kestabilan timbunan bila ada beberapa area yang mengharuskan desain tinggi timbunan melebihi control guide batasan tinggi dan kemiringan timbunan.

Ruas jalan tol Serang - Panimbang berada dalam tahap konstruksi yang direncanakan sepanjang $50 \mathrm{~km}$ pada tahap awal. Investigasi penyelidikan tanah telah dilakukan untuk menunjang proses desain geoteknik di sepanjang $50 \mathrm{~km}$. Penyelidikan tanah yang dilakukan adalah site investigation dan pengujian laboratorium. Uji lapangan berupa borlog dan uji laboratorium berupa index properties, proctor, consolidation dll. Hasil penyelidikan tanah menunjukkan bahwa kondisi tanah di daerah sepanjang rencana jalan tol adalah mayoritas tanah yang bersifat kohesif, terdapat pula beberapa spot kasus khusus seperti tanah organik dan tanah lunak di sepanjang rencana jalan. Pembahasan akan berfokus pada daerah-daerah yang bukan termasuk kasus khusus. Hasil penyelidikan tanah digunakan untuk menghitung kestabilan timbunan jalan.

Timbunan pada rencana jalan tol Serang Panimbang tertinggi sebesar 15 meter dengan rencana kemiringan slope sepanjang $50 \mathrm{~km}$ sama yaitu 1:2. Artikel ini membahas mengenai batasan ketinggian timbunan yang dihubungkan dengan nilai N-spt tanah dasar. Perhitungan kestabilan tanah menggunakan Slope-W 2012 untuk statik. Maka batas timbunan langsung dapat diketahui pada suatu area di sepanjang 
rencana jalan dengan melihat nilai $\mathrm{N}$-spt tanah dasar area tersebut.

\section{Numerical Parameter dan Analisis}

1. Batasan kasus

Tol Jalan Serang - Panimbang tahap pertama $50 \mathrm{~km}$ mempunyai titik penyelidikan untuk perencanaan desain awal sebesar boring 100 buah, sondir 98 buah, dan data lab \pm 3 sampel setiap boring. Mayoritas jenis tanah $50 \mathrm{~km}$ awal jalan adalah tanah kohesif. Batasan kasus ditunjukkan hanya untuk tanah kohesif, tidak termasuk tanah khusus seperti organik, gambut dan lain sebagainya. Hasil penyelidikan lapangan dan lab dipilihan dan distatistikan menurut batasan kasus di atas. Maka hasil analisis ini akan berlaku pada tanah kohesif, tidak termasuk tanah khusus seperti organik, gambut dan lain sebagainya.

2. Pembebanan

a. Beban lalu lintas

Berdasarkan Panduan Geoteknik 4 (2002), beban lalu lintas ditambahkan untuk analisis stabilitas timbunan jalan.

\section{Tabel 1. Beban Lalu Lintas dalam} Analisis

\begin{tabular}{|c|c|}
\hline Kelas Jalan & Beban Lalu Lintas (kPa) \\
\hline I & 15 \\
\hline II & 12 \\
\hline III & 12 \\
\hline
\end{tabular}

Sumber: Panduan Geoteknik 4 (2002)

b. Beban perkerasan

Beban perkerasan dengan detail slab beton $30 \mathrm{~cm}$, lean Concrete $15 \mathrm{~cm}$, dan Agregat kelas A $15 \mathrm{~cm}$.

$\mathrm{qm}=2,4(0,3+0,15)+2,2(0,15)$

$\mathrm{qm}=1,08+0,33=1,29 \mathrm{t} / \mathrm{m}^{2}$

$\mathrm{qm}=12,9 \mathrm{kN} / \mathrm{m}^{2}$

Beban total
$\mathrm{qt}=\mathrm{qm}+\mathrm{qL}$

$\mathrm{qt}=27,9 \approx 30 \mathrm{kN} / \mathrm{m}^{2}$

Beban Lalu Lintas $=15 \mathrm{kPa}$

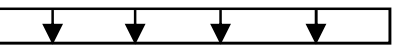

Perkerasan $=12.9 \mathrm{kPa}$

Timbunan

\section{Gambar 1. Ilustrasi Surcharge Load pada} Timbunan

Sumber: Hasil Analisis, 2020

Maka surcharge load yang berada di atas timbunan adalah beban lalu lintas dan perkerasan $\mathrm{qt}=30 \mathrm{kN} / \mathrm{m}^{2}$

c. Parameter dan kriteria

- Parameter

Perhitungan kestabilan membutuhkan parameterparameter tanah seperti c, $\phi$, dan $\Upsilon$. Parameter tersebut diambil berdasarkan statistik hubungan $\mathrm{N}$ spt (penyelidikan lapangan) dengan data laboratorium, sehingga menghasilkan ketentuan nilai parameter-parameter tiap lapisan dan ketentuan parameter timbunan dalam artikel.

Tabel 2. Parameter Lapisan Tanah Dasar

\begin{tabular}{|c|c|c|c|c|}
\hline Lapis & $\mathrm{N}-\mathrm{spt}$ & $\mathrm{c} \mathrm{kN} / \mathrm{m} 2$ & $\phi$ & $\Upsilon \mathrm{kN} / \mathrm{m} 3$ \\
\hline 1 & $0-4$ & 4 & 10 & 15 \\
\hline 2 & $5-8$ & 14 & 10 & 16 \\
\hline 3 & $9-12$ & 25 & 10 & 16 \\
\hline 4 & $13-15$ & 36 & 10 & 17 \\
\hline 5 & $16-20$ & 44 & 10 & 17 \\
\hline 6 & $20-25$ & 55 & 10 & 18 \\
\hline 7 & $26-30$ & 69 & 10 & 18 \\
\hline
\end{tabular}

Sumber: Hasil Analisis (2020) 
Tabel 3. Parameter Timbunan

\begin{tabular}{|l|c|c|c|}
\hline Parameter & $\begin{array}{c}\mathrm{c} \\
\mathrm{kN} / \mathrm{m}^{2}\end{array}$ & $\phi$ & $\Upsilon \mathrm{kN} / \mathrm{m}^{3}$ \\
\hline Timbunan & 30 & 10 & 18 \\
\hline
\end{tabular}

Sumber: Hasil Analisis (2020)

- Faktor keamanan slope

Nilai acuan faktor keamanan lereng timbunan bernilai minimum 1.5 menjadi patokan perhitungan statik dengan metode Morgenstern-price. Hal berikut mengacu pada kriteria SNI GEOTEKNIK 8460:2017 tentang persyaratan dan perancangan geoteknik.

- Variasi

Variasi pemodelan yang digunakan dalam artikel adalah nilai $\mathrm{N}$-spt tanah dasar (jenis lapisan tanah) dan tinggi timbunan. Tanah dasar dibagi menjadi 2 lapis dengan detail ketebalan tiap lapis adalah $5 \mathrm{~m}$. Penggunaan ketebalan tiap lapisan tanah dasar sebesar $5 \mathrm{~m}$ untuk menopang timbunan, didasarkan dengan hasil penyelidikan lapangan bor log yang menunjukkan bahwa keadaan rata-rata lapisan tanah di daerah Serang - Panimbang memiliki tebal kurang lebih $5 \mathrm{~m}$ tiap lapisannya.

- Variasi kedua dalam artikel ini adalah tinggi timbunan. Rencana timbunan tertinggi adalah $15 \mathrm{~m}$ sehingga variasi tinggi timbunan dimulai dari $1-15 \mathrm{~m}$. Dengan menggabungkan dua variasi tersebut maka artikel melakukan pemodelan dengan acuan Tabel 4 . Sketsa pemodelan pada Gambar 2 .

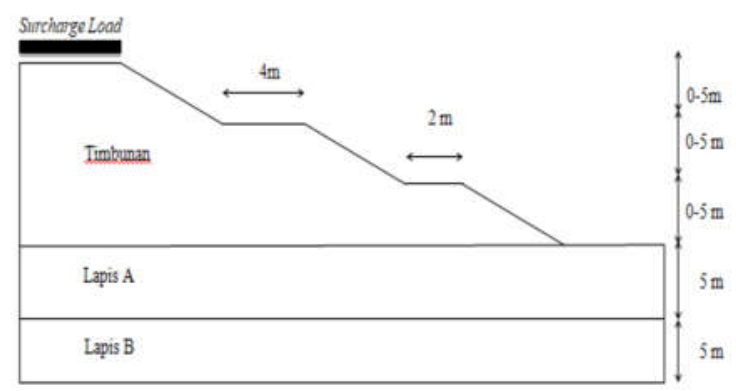

Gambar 2. Potongan Melintang Jalan Tol Sumber: Hasil Analisis, 2020

\section{Tabel 4. Rencana Variasi Pemodelan Faktor Keamanan Timbunan}

\begin{tabular}{|c|c|}
\hline Lapis Tanah & Tinggi Timbunan $(\mathrm{m})$ \\
\hline [A पadII & $\begin{array}{lllllllllllllll}1 & 2 & 3 & 4 & 5 & 6 & 7 & 8 & 9 & 10 & 11 & 12 & 13 & 14 & 15\end{array}$ \\
\hline $\begin{array}{l}1 \text { dan } 2 \\
2 \text { dan } 3 \\
3 \text { dan } 4 \\
4 \text { dan } 5 \\
5 \text { dan } 6\end{array}$ & $\begin{array}{l}\text { Variasi Pemodelan terdiri dari } 2 \text { lapis tanah dan tinggi timbunan, kemudian } \\
\text { pemodelan dirunning pada Geoslope 2012. Hasil yang diambil dari hasil } \\
\text { running tersebut adalah faktor keamanan slope timbunan }>1.5\end{array}$ \\
\hline
\end{tabular}

Sumber: Hasil Analisis (2020)

Berikut pemodelan dengan menggunakan geoslope berdasarkan variasi tinggi timbunan dan lapisan tanah.

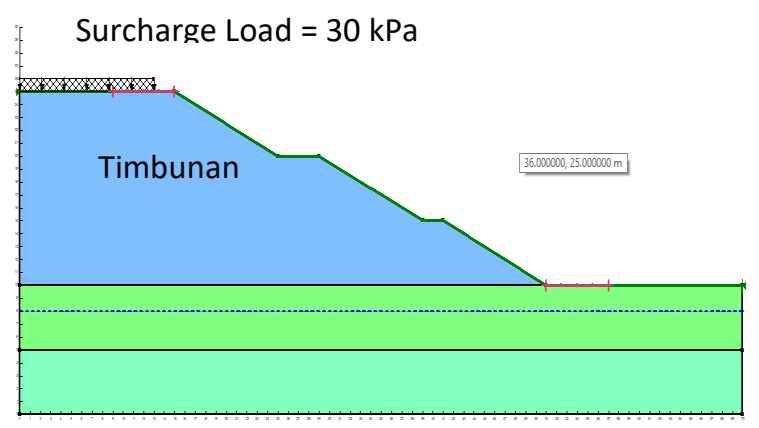

Gambar 3. Pemodelan Timbunan Geoslope

Sumber: Hasil Analisis, 2020

\section{Hasil dan Pembahasan}

Hasil faktor keamanan berdasarkan variasi tinggi timbunan dengan lapisan tanah dasar dengan pengambilan batas faktor keamanan timbunan sebesar 1.5 terdapat pada Tabel 5 . 


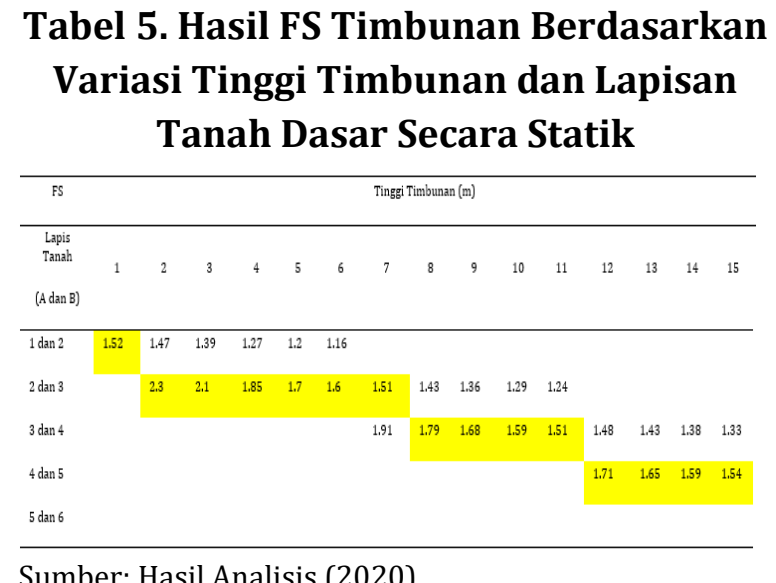

Sumber: Hasil Analisis (2020)

Hasil pemodelan menunjukkan bahwa hubungan faktor keamanan terhadap tinggi timbuanan memiliki kecenderungan semakin menurun. Hal tersebut diakibatkan semakin tinggi beban yang harus ditanggung oleh tanah dasar dan kemampuan slope menjaga stabilitas akibat timbunan yang semakin tinggi terlihat pada Gambar 4 (statik) serta didetailkan pada Gambar 5 (statik)

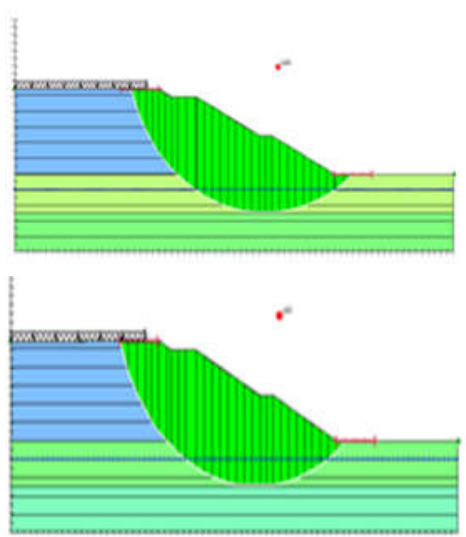

Gambar 4. Hasil Model Timbunan $11 \mathrm{~m}$ Lapisan 2 dan 3, FS 1.24 (a), Hasil Model Timbunan $11 \mathrm{~m}$ Lapisan 3 dan 4, FS 1.51(b)

Sumber: Hasil Analisis, 2020

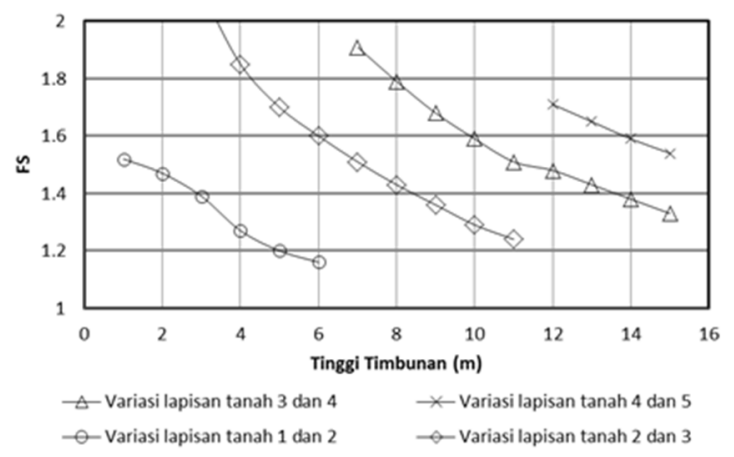

Gambar 5. Grafik Hubungan Faktor Keamanan Terhadap Perubahan Lapisan Tanah dan Tinggi Timbunan Secara Statik

Sumber: Hasil Analisis, 2020

Pada hubungan faktor keamanan terhadap perubahan lapisan tanah, hasil memperlihatkan kecenderungan kenaikan karena semakin tinggi parameter tanah (c, $\phi$, dan $\Upsilon$ maka akan semakin besar pula daya dukung dari timbunan tersebut, terlihat pada Gambar 6 dan Gambar 5.

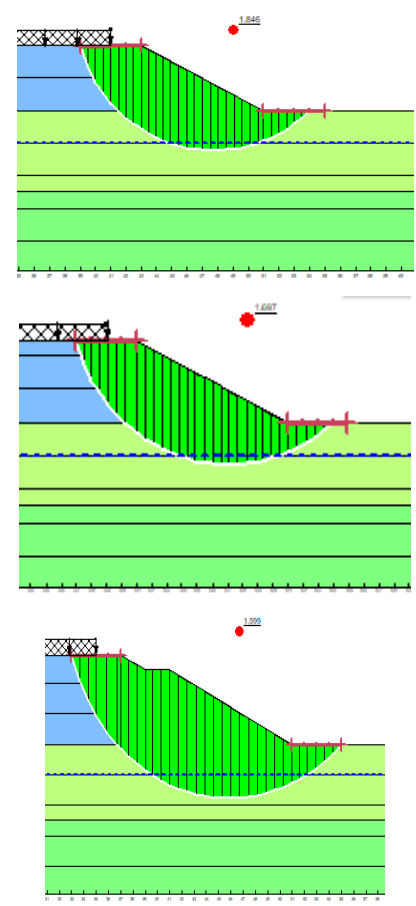

Gambar 6. Timbunan $4 \mathrm{~m}$, lapisan 2 dan 3, FS 1.85 (a), Timbunan $5 \mathrm{~m}$, lapisan 2 dan 3, FS 1.7 (b), Timbunan 6 m, lapisan 2 dan 3, FS 1.6 (c) 
Hasil faktor keamanan berdasarkan variasi lapisan tanah dasar dan tinggi timbunan dikelompokkan sesuai dengan batas minimum desain yaitu FS 1.5 sesuai dengan Tabel 5 dan 6.

Dengan demikian, Untuk statik maka Slope dengan ketinggian maksimum $7 \mathrm{~m}$ harus berada di tanah dasar lapis 2. Slope dengan ketinggian antara 8 - $11 \mathrm{~m}$ harus berada di tanah dasar lapis 3. Sedangkan slope dengan ketinggian antara 12 - $15 \mathrm{~m}$ harus berada di tanah dasar lapis 4 .

Kemudian hasil lapisan tanah dasar dihubungkan dengan nilai $\mathrm{N}$-spt yang mewalikili sesuai dengan Tabel 2. Maka artikel mendapatkan ketentuan batasan tinggi timbunan dengan nilai $\mathrm{N}$-spt sebagai berikut:

Slope dengan ketinggian maksimum $7 \mathrm{~m}$ harus berada di tanah dasar dengan $\mathrm{N}$-spt 58. Slope dengan ketinggian antara 8-11 m harus berada di tanah dasar dengan $\mathrm{N}$-spt 912. Sedangkan slope dengan ketinggian antara 12-15 m harus berada di tanah dasar dengan N-spt 13-15.

\section{Kesimpulan}

Dengan demikian desain slope sepanjang Serang - Panimbang dalam kondisi tanah normal (bukan kasus tanah khusus) dapat mengacu pada guideline perhitungan kestabilan timbunan seperti dibawah ini, Kestabilan Statik

1. Apabila slope memiliki ketinggian maksimum $7 \mathrm{~m}$ maka timbunan harus berada di tanah dasar dengan $\mathrm{N}$-spt 5 8.

2. Apabila slope memiliki ketinggian maksimum 8 - $11 \mathrm{~m}$ maka timbunan harus berada di tanah dasar dengan $\mathrm{N}$ spt $9-12$.

3. Sedangkan slope dengan ketinggian antara 12 - $15 \mathrm{~m}$ harus berada di tanah dasar dengan N-spt 13 - 15.
Hasil artikel ini dapat dijadikan acuan desain slope statis sepanjang konstruksi area Serang - Panimbang $50 \mathrm{~km}$ untuk mengontrol kestabilan slope timbunan jalan.

\section{Daftar Pustaka}

Abramson, L. W., Thomas, S. L., Sunil, S., Glenn, M. B, (2002), Slope Stability and Stabilization Methods. John Wiley \& Sons, Inc, New York.

Budhu, Muni (2011). Soil Mechanics and Foundation 3rd Edition. New York : John Wiley \& Sons, Inc.

Craig, R.F. (2004). Craig's Soil Mechanics 7th Edition. New York : Spon Press.

Cheng, Y.M. and Lau, C.K. (2008). Slope Stability Analysis and Stabilization. Great Britian : Antony Rowe, Chippenham, Wilts.

Das, Braja M., (2010). Principles of Geotechnical Engineering (7ed.).

Stamford : Cengage Learning.

Departemen Permukiman dan Prasarana Wilayah, 2002, Panduan Geoteknik 4 Desain dan Konstruksi, WSP International, Indonesia.

GEO-SLOPE, (2012), Stability Modeling With SLOPE/W 2012 Version. Calgary, Alberta, Canada.

Hardiyatmo, H. C, (2006). Mekanika Tanah 1, Gadjah Mada University Press, Yogyakarta.

Kulhawy, F.H.\& Mayne, P.W. (1990). Manual on Estimating Soil Properties for Foundation Design. New York: Holister Hall.

Morgenstern, N.R. and Price, V.E. (1965)

The Analysis of the Stability of Generalised Slip Surfaces. Géotechnique, 15, 79-93.

US Army Corps of Engineers (2003) Engineering and Design-Slope Stability (PDF). US Army Corps of Engineers, Washington DC. 
Wyllie, Duncan C., \& Christopher W. Mah. 2004. Rock Slope Engineering: Civil and Mining. 4rd. (ed). New York : Spoon Press. London.

SNI Geoteknik 8460:2017. 2017. Persyarataan Perancangan Geoteknik. BSN 2017. 
